LAWRENCE LIVERMORE N A T IO N A L LABORATORY

VACET Software Engineering Group's Progrees Report: February 2007

Hank Childs

March 6, 2007 
This document was prepared as an account of work sponsored by an agency of the United States Government. Neither the United States Government nor the University of California nor any of their employees, makes any warranty, express or implied, or assumes any legal liability or responsibility for the accuracy, completeness, or usefulness of any information, apparatus, product, or process disclosed, or represents that its use would not infringe privately owned rights. Reference herein to any specific commercial product, process, or service by trade name, trademark, manufacturer, or otherwise, does not necessarily constitute or imply its endorsement, recommendation, or favoring by the United States Government or the University of California. The views and opinions of authors expressed herein do not necessarily state or reflect those of the United States Government or the University of California, and shall not be used for advertising or product endorsement purposes.

This work was performed under the auspices of the U.S. Department of Energy by University of California, Lawrence Livermore National Laboratory under Contract W-7405-Eng-48. 


\title{
VACET Software Engineering Group's Progress Report: February 2007
}

\author{
Hank Childs, VACET Chief Software Engineer \\ February 26, 2007
}

Each document in this series will summarize a teleconference of the VACET Software Engineering Group (SEG), which in turn summarizes the progress of the previous month. For February 2007, the teleconference took place on February $26^{\text {th }}$.

\begin{tabular}{|l|l|}
\hline \multicolumn{1}{|c|}{ Participant } & \multicolumn{1}{c|}{ Organization } \\
\hline Sean Ahern & ORNL \\
\hline Hank Childs & LLNL \\
\hline Marty Cole & UUtah \\
\hline Jeremy Meredith & ORNL \\
\hline Gunther Weber & LBL \\
\hline Brad Whitlock & LLNL \\
\hline
\end{tabular}

(Brad Whitlock is not formally part of the VACET team, but he has been on loan from the ASC program -- and charging VACET account numbers -- to perform some VisIt enhancements for which he is very well qualified.)

\section{Organizational updates:}

There are no formal organizational updates. Ken Joy does believe that the UCD SEG member will be coming online soon.

\section{Technical updates:}

The teleconference consisted of a series of site reports from each of the four participating sites. Technical discussions about the work being done at each site took place during each site report.

1This document is UCRL-TR-228714. 
LBL update: Gunther participated in conversations with Phil Colella and John Bell regarding meeting their needs (along with Wes Bethel and Hank Childs). Gunther is still learning VisIt, both as a user and as a developer. Gunther explored issues with making "plugins" work on Macs and shared his findings with the VisIt team. Gunther has continued to pursue line integral convulution (LIC) work with Louis Feng. Gunther has uncovered a problem with the interpolation scheme Louis was using where two polylines directed at the same face can get stuck going back and forth in a loop. Gunther has ideas for how to fix this, but is still waiting a further meeting with Louis.

LLNL update: Brad Whitlock implemented one variant of visual spreadsheets in VisIt. The variant is the one used by "ChomboVis". (The other variant of interest is the one used by AMRVis.) More information about that variant can be found in the document (written by Brad) on visual spreadsheets located on the VACET wiki. Wes Bethel passed along a screenshot to Phil Colella, who responded that it appears that VACET is making good progress. In addition to the actual plot, Brad added key infrastructure to VisIt to support the plot. The biggest infrastructure changes were: (1) allowing a plot to modify its attributes from the viewer (which meant that plots must be able to access the "ViewerProxy" interface), (2) allowing a plot to access the full meta-data information about the data it was plotting, and (3) allowing a plot to instantiate and manage its own window, even one that is not Qt-based.

Hank Childs traded his VACET account number to Brad, so Hank did less VACET work over the past month. However, the time he did charge was spent in planning the migration from ClearCase to Subversion for the VisIt project. VisIt is currently not a project that can be distributed by many organizations, which is a key limitation, especially in the context of VACET where many organizations are participating. Using Subversion (coupled with the support offered by the SciDAC Outreach Center) will allow for this multi-organization development to take place. In terms of actual work, Hank developed a script that will transfer the VisIt code base from VisIt's ClearCase repository to a Subversion repository and maintain versioning history. Hank also produced a document describing the steps of the transition process and vetted that document with the group. Hank will put that document on the VACET wiki in the upcoming month.

ORNL update: Jeremy Meredith explored enhancing parallel coordinates plots with histogram-based rendering, which will allow the technique to be 
more effective for very large data sets. This work is applicable to many application domains. He is integrating his work with VisIt's existing parallel coordinates plot. In the upcoming month, he hopes to address parallelization issues.

Climate customers have suggested the functionality in NCVTK and NCO tools are very powerful and would like their functionality to be included in our delivery vehicles. Jamison Daniel is investigating. (Note from Hank: I do not know anything about the tools that are being described here and should learn more.)

We continue to discuss the statistics package ' $\mathrm{R}$ '. We believe that statisticsdriven visualization will be important for the peta-scale analysis we will be asked to do in the near future. Summary: Jeremy believes that there are different levels of integration possible with 'R'. George Ostrochov (who did not call in) believes that we should look at integrating serial ' $R$ ' with a distributed memory parallel implementation. Sean points out that the SDM center is working on a parallel 'R', but believes that what they are working on will not meet our needs. Sean agrees to pursue this issue with the SDM folks.

Sean has been investigating SCIRun3. He is looking at the Poincare plot that Allen Sanderson put together.

UCDavis update: There are currently no members of the SEG from UCDavis.

UUtah update: Marty has been continuing to refactor and simplify the code. He characterized his first pass as too agreessive and some of his changes as oversimplifications. This subsequent pass has focused on fixing those issues and also on productizing the existing code. (The code has evolved with many hands touching it and Marty is trying to ensure that the library will be sufficiently hardened when it is plugged into additional applications.) Marty believes in the next week or two he will have SCIRun working with the library he has isolated. The next step will be to add the right level of functionality to support distributed memory volume rendering. Hank and Marty agree to have an off-line conversation to discuss this.

There is also discussion of how to verify that the library is working correctly once in VisIt. Apparently, SCIRun reads a format that is similar to VisIt's 
"brick of bytes/values", so there is a possible easy path there. More discussions on this issue can take place as need calls for it. 